\title{
SISTEMA DE ACOMPANHAMENTO DE CRESCIMENTO ANIMAL MODULO WEB 2.0
}

\author{
Arthur Scardini Domingues ${ }^{1}$ \\ Diego Nicacio Viana ${ }^{2}$ \\ Rodrigo Gonçalves Barbosa ${ }^{3}$ \\ Daniel Emilio de Souza ${ }^{4}$ \\ Carlos Alexandre Siqueira da Silva ${ }^{5}$ \\ Cesar Otaviano Penna Junior 6
}

Resumo: Com a evolução dos processos no setor produtivo, a tecnologia da informação se faz indispensável para o auxílio da competitividade mercadológica desse setor. O presente trabalho tem por objetivo, a criação de uma ferramenta computacional que auxilia o produtor rural no acompanhamento do desenvolvimento das fêmeas de reposição do rebanho de propriedades produtoras de leite. Embasado nas técnicas de análise de sistemas, foi possível realizar um levantamento de requisitos, para que fosse definida as características do sistema. O software atendeu as necessidades elencadas na fase de análise, foi possível realizar o rateio dos gastos pelo peso total dos animais, determinando o custo de cada quilograma dos animais, permitindo ao produtor acompanhar de maneira satisfatória o desenvolvimento zootécnico e econômico dos animais, assim tornando a ferramenta um poderoso aliado do produtor no controle de sua produção.

Palavras-chave: Integridade; Setor Produtivo; Sistemas; Software.

\footnotetext{
${ }^{1}$ Tecnologia em Analise e Desenvolvimento de Sistemas/Instituto Federal do Espírito Santo - Campus de Alegre, Brasil. E-mail: arthurdomingues91@hotmail.com.

2 Tecnologia em Analise e Desenvolvimento de Sistemas/Instituto Federal do Espírito Santo - Campus de Alegre, Brasil. E-mail: diegonicacio@live.com.

${ }^{3}$ Tecnologia em Analise e Desenvolvimento de Sistemas/Instituto Federal do Espírito Santo - Campus de Alegre, Brasil. E-mail: rodrigo.barbosa@ifes.edu.br.

${ }^{4}$ Tecnologia em Analise e Desenvolvimento de Sistemas/Instituto Federal do Espírito Santo - Campus de Alegre, Brasil. E-mail: daniel377@hotmail.com.

${ }^{5}$ Docente Mestre/Instituto Federal do Espírito Santo - Campus de Alegre, Brasil. E-mail: cassilva@ifes.edu.br.

${ }^{6}$ Docente Mestre/Instituto Federal do Espírito Santo - Campus de Alegre, Brasil. E-mail: copenna@ifes.edu.br.
} 